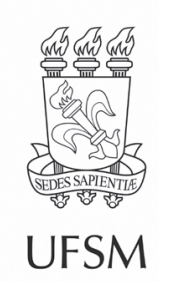

\title{
Artigos
}

\section{Efeitos da sazonalidade sobre a fenologia e a fisiologia de Parkia platycephala Benth (Fabaceae, Caesalpinioideae) em área de Cerrado}

\author{
Seasonality effects on the phenology and physiology of Parkia \\ platycephala Benth (Fabaceae, Caesalpinioideae) in Cerrado
}

Valdelice Oliveira Lacerda' ${ }^{\oplus}$, Ana Maria Mapeli" $\odot$

'Universidade Federal de Lavras, Lavras, MG, Brasil

"Universidade Federal do Oeste da Bahia, Barreiras, BA, Brasil

\section{RESUMO}

Devido à sua natureza séssil, as plantas desenvolveram diversos mecanismos para manter sua reprodução e se defender em condições estressantes. Tanto o metabolismo primário quanto o secundário são afetados por mudanças ambientais nas diferentes fases de desenvolvimento vegetal. Sendo assim, é importante conhecer os mecanismos de defesa e resistência às intempéries ambientais de plantas adaptadas às diversas condições ambientais, a exemplo de Parkia platycephala. Essa espécie é endêmica do Brasil e apresenta diversas potencialidades de uso para fins farmacológicos, forrageiro, madeireiro, ornamental e ecológico. Dessa forma, este trabalho se propõe a analisar a relação entre sazonalidade climática, fenologia e fisiologia de Parkia platycephala. O estudo foi conduzido em área de Cerrado sensu stricto, na região da Serra da Bandeira $\left(12^{\circ} 05^{\prime} \mathrm{S}\right.$ e $\left.45^{\circ} 02^{\prime} \mathrm{W}\right)$, Barreiras, Bahia. As fases fenológicas de Parkia platycephala foram observadas mensalmente, seguindo a metodologia de Fournier. O material vegetal (folhas) para as análises fisiológicas foi coletado dos mesmos indivíduos selecionados para fenologia, dos quais foram quantificados pigmentos fotossintéticos, teor de fenóis totais, atividade antioxidante, teor de açúcares solúveis totais (AST), açúcares redutores (AR) e açúcar não redutor (ANR). Parkia platycephala apresentou padrão vegetativo semidecidual sazonal e um padrão reprodutivo anual. A baixa disponibilidade hídrica foi o fator ambiental que mais afetou os processos fisiológicos, diminuindo a produção de clorofila a e carotenoides e promovendo o aumento na produção de clorofila b, fenóis totais e carboidratos solúveis não estruturais. No geral, a atividade antioxidante não enzimática em Parkia platycephala foi alta, sendo 3,66 vezes superior ao ácido ascórbico (Vitamina C). Dessa forma, a espécie demostrou possuir mecanismos eficazes para manter seus processos fisiológicos ativos suportando a seca e a intensa insolação durante o ano, porém a produção de carboidratos é afetada por essas variações ambientais refletindo negativamente sobre as suas fenofases, principalmente sobre a fenofase reprodutiva.

Palavras-chave: Faveira; Estresse abiótico; Metabolismo vegetal 


\section{ABSTRACT}

Plant species have developed a great number of mechanisms to maintain their reproduction and defend themselves during stressful conditions. Both primary and secondary metabolisms are affected by environmental changes at different stages of plant development. Thus, it is important to know plant defense and resistance mechanisms to environmental variations adapted to different environmental conditions. Parkia platycephala is an endemic species to Brazil and has several potential uses for pharmacological, forage, wood, ornamental and ecological purposes. Herein, we analyzed the relationship between climatic seasonality, phenology and physiology of Parkia platycephala. The study was carried out in a Cerrado sensu stricto area located in the region of Serra da Bandeira $\left(12^{\circ} 05^{\prime} \mathrm{S}\right.$ and $\left.45^{\circ} \mathrm{O} \mathrm{z}^{\prime} \mathrm{W}\right)$, Barreiras, Bahia, Brazil. The phenological phases of Parkia platycephala were observed monthly following the methodology of Fournier. Leaves from the same individuals selected for phenological evaluations were sampled for physiological analyzes and the photosynthetic pigments, total phenol content, antioxidant activity, total soluble sugars (TSS), reducing sugars (RS) and non-reducing sugar (NRS) were quantified. Parkia platycephala presented a seasonal semi-deciduous vegetative pattern and annual reproductive pattern. The low water availability was the main environmental driver which most affected the physiological processes, reducing chlorophyll a and carotenoid production and promoting an increase in chlorophyll b, total phenol and non-structural soluble carbohydrate production. The non-enzymatic antioxidant activity in Parkia platycephala was high, presenting 3.7-times higher values than ascorbic acid (Vitamin C). Thus, this species presents effective mechanisms to maintain its active physiological processes, supporting droughts and intense sunshine throughout the year; however, its carbohydrate production is negatively affected by environmental shifts, thereby reflecting their phenophases, specifically on the reproductive phenophase.

Keywords: Faveira; Abiotic stress; Plant metabolism

\section{INTRODUÇÃO}

O Cerrado é um bioma com expressiva riqueza florística que abriga 12.097 espécies com sementes, das quais 4.252 são endêmicas (THE BRAZIL FLORA GROUP, 2015). Essa diversidade na flora é apontada como resultado das características edáficas e climáticas desse bioma, juntamente com a dinâmica do fogo, que exerce uma pressão seletiva sobre suas espécies, conferindo-as aspectos morfológicos, anatômicos e fisiológicos particulares. Os diversos processos meteorológicos que atuam de forma conjunta sobre o Cerrado o conferem características climáticas marcantes, com duas estações bem definidas na maior parte de seu território: uma chuvosa, de outubro a abril; e uma estação seca, marcada por profunda deficiência hídrica, que se inicia em maio e se estende até setembro (SILVA; ASSAD; EVANGELISTA, 2008). 
Dentro desse contexto com diversas intemperes ambientais, o estudo dos padrões fenológicos das plantas do Cerrado se mostra uma ferramenta importante para a melhor compreensão das dinâmicas desse bioma, uma vez que as fenofases variam entre as formas de vida e são fortemente associadas às variações climáticas. Além disso, por se tratar de uma ciência multidisciplinar e envolver áreas de estudos como biometeorologia, ecologia e biologia evolutiva, a fenologia pode apresentar grande contribuição para a atual biologia da conservação (MORELLATO et al., 2016).

Um dos fatores intrínsecos às plantas e primordiais para plena produção nas diferentes fenofases é a atividade fotossintética, que produz carboidratos a partir de energia luminosa. A luz absorvida pelos carotenoides é transferida para a clorofila b e, posteriormente, para a clorofila a, que direciona essa energia para os centros de reação (TAIZ et al., 2017). Para além da função energética dos açúcares produzidos na fotossíntese, alguns estudos estão buscando elucidar algumas funções biológicas de sinalização dessas moléculas nas plantas durante a embriogênese, o estabelecimento de plântulas, o crescimento, o metabolismo, a transição juvenil-adulto, a floração e a senescência (LI; SHEEN, 2016), processos extremamente associados à produtividade.

Fatores bióticos e abióticos também influenciam os níveis de espécies reativas de oxigênio, alterando a homeostase redox necessária para a regulação da bioatividade. Para combater as espécies reativas de oxigênio, as plantas possuem dois mecanismos de atuação, incluindo a atividade antioxidante enzimática, que elimina essas espécies reativas de oxigênio e equivale a uma importante defesa primária contra esses radicais livres gerados sob condições de estresse, bem como o mecanismo não-enzimático que atua sequestrando os radicais livres e protegendo a planta por meio de algumas moléculas, como a-tocoferol (vitamina E), $\beta$-caroteno, ácido ascórbico (vitamina C) e os compostos fenólicos (REDDY, CHAITANYA, VIVEKANANDAN, 2004).

Nesse cenário de estresse provocado pelas variações ambientais, encontra- 
se Parkia platycephala Benth., uma espécie arbórea, pertencente à família botânica Fabaceae e endêmica do Brasil, distribuindo-se pelas regiões Norte, Nordeste e CentroOeste, presente nos biomas Amazônia, Caatinga e Cerrado. Possui porte arbóreo, podendo alcançar até $18 \mathrm{~m}$ de altura e uma copa ampla. Suas folhas são alternas, bipinadas, com 9-18 pares de pinas e com uma glândula circular ou elíptica entre a base do pecíolo e o primeiro par de folíolos. Possui inflorescência do tipo capítulo globoso com 3,8-5,2cm de diâmetro, com coloração vermelho intenso e dispostas nos ramos florais em pedúnculos alternos (às vezes opostos) com cerca de $50 \mathrm{~cm}$. Possui dois tipos de flores, uma monoclina, com as estruturas sexuais masculinas e femininas, localizada na porção lateral do capítulo, e outra infértil especializada na secreção de néctar, disposta na região central do capítulo. As vagens dessa espécie são, geralmente, oblongas, glabras, com valvas levemente viscosas, corrugadas e indeiscentes. Cada vagem possui cerca de 34 sementes dispostas em duas séries e tegumento marrom claro (HOPKINS, 1986). Essa espécie apresenta variados usos na pecuária, na marcenaria, no mercado farmacológico, além de potencial ornamental e ecológico (LORENZI, 2002). Porém, ainda são inexistentes estudos que busquem relacionar fatores ambientais à fenologia e aos processos fisiológicos dessa espécie, havendo a necessidade de mais informações sobre o seu manejo e habitat, haja visto que há uma intensa pressão ambiental sobre os biomas onde as populações de Parkia platycephala se encontram.

Dessa forma, estudos que inter-relacionam diferentes fatores que afetam a produção e o desenvolvimento vegetal no Cerrado contribuem para uma compreensão mais ampla desse bioma, por meio do fornecimento de informações para o desenvolvimento de projetos de conservação e manejo do mesmo. Sendo assim, este trabalho teve como objetivo analisar a relação entre sazonalidade climática, fenologia e fisiologia de Parkia platycephala. 


\section{MATERIAL E MÉTODO}

\subsection{Coleta dos dados}

O estudo foi conduzido em área de Cerrado sensu stricto, na região da Serra da Bandeira $\left(12^{\circ} 05^{\prime} \mathrm{S}\right.$ e $\left.45^{\circ} 02^{\prime} \mathrm{W}\right)$, Barreiras, Bahia. Essa região possui clima do tipo Aw, segundo classificação de Köppen, com inverno seco e verão chuvoso. A temperatura média varia entre a mínima de $20,3^{\circ} \mathrm{C}$ e a máxima de $31,5^{\circ} \mathrm{C}$, com precipitação média anual de $1500 \pm 500$ mm (SOARES NETO; BEZERRA; MOSCON, 2013).

As visitas a campo foram feitas mensalmente, de janeiro a dezembro de 2017, quando foram realizadas as observações fenológicas e as coletas do material vegetal para as análises de pigmentos fotossintetizantes, carboidratos solúveis não estruturais, fenóis totais e atividade antioxidante. Para as análises fisiológicas foram selecionadas folhas maduras e com aspecto saudável, sem sinais de ataque de patógenos ou herbívoros. O material coletado foi processado no Laboratório de Botânica da Universidade Federal do Oeste da Bahia e, então, armazenado em freezer $-80^{\circ} \mathrm{C}$ para posteriormente serem submetidos às respectivas metodologias de determinação.

Uma amostra de Parkia platycephala foi herborizada e depositada no Herbário da Universidade Federal do Oeste da Bahia (voucher: BRBA7597), para posteriores consultas.

Dados climáticos de precipitação, temperatura média e insolação de janeiro a dezembro de 2017 foram obtidos no site do Instituto Nacional de Meteorologia (INMET) para serem relacionados com o período fenológico e as análises fisiológicas de Parkia platycephala.

\subsection{Fenologia}

Para o estudo da fenologia, foram marcados 20 indivíduos adultos e aparentemente saudáveis, os quais foram avaliados quanto às fases fenológicas vegetativas (abscisão e brotamento) e reprodutivas (floração e frutificação), seguindo 
a classificação de Fournier (1974).

A magnitude da presença da fenofase foi estimada a partir de uma comparação entre os indivíduos, tendo como base o espécime com a maior densidade de presença da fenofase monitorada na espécie, levando-se em consideração a área da copa proporcional de cada indivíduo. Com os valores obtidos em campo, foi calculada a porcentagem de intensidade de cada fenofase.

Para análise do padrão fenológico foi utilizada a classificação de Newstron, Frankie e Baker (1994). Para tanto, observou-se a frequência e a duração das fenofases, seguindo o critério de frequência que considera o número de ciclos por ano (um ciclo consiste de um episódio de fenofase seguido por um intervalo sem a fenofase) e apresenta quatro classes principais: contínuo - quando a fenofase apresenta-se continuamente ou com interrupções breves; subanual - quando a fenofase apresenta mais de um ciclo por ano; anual - quando a fenofase apresenta um ciclo no período de um ano; e supra-anual - quando a fenofase apresenta um ciclo em um período superior a um ano ou quando os episódios da fenofase abordada ocorrem separados por intervalos superiores a um ano.

\subsection{Pigmentos Fotossintetizantes}

A quantificação dos pigmentos fotossintetizantes seguiu o método proposto por Lichthenthaler (1987), sendo que foram pesados $3 \mathrm{~g}$ de folhas maduras de Parkia platycephala que, posteriormente, foram imersos em acetona $80 \%$ e triturados, com auxílio de Homogeneizador/Triturador TE-102. Em seguida, o material foi filtrado em papel filtro, seguido de quatro lavagens, e o volume do sobrenadante padronizado para $100 \mathrm{~mL}$ para, então, se fazer a leitura em espectrofotômetro, nas absorbâncias 470, 646,8 e 663,2 nm, correspondendo aos pigmentos carotenoides, clorofila b e clorofila a, respectivamente. A partir dos valores obtidos, foi calculada a concentração de cada pigmento e os resultados foram expressos em gramas de pigmento por quilograma de massa fresca ( $\left.\mathrm{kg}^{-1} \mathrm{MF}\right)$. 


\subsection{Carboidratos Solúveis não estruturais}

Para a quantificação dos teores de açúcar solúvel total (AST), açúcar redutor (AR) e açúcar não redutor (ANR), $3 \mathrm{~g}$ do material vegetal foram macerados em etanol $80 \%$, seguido de filtração e três lavagens, em que o volume combinado foi completado para $100 \mathrm{~mL}$ com etanol $80 \%$.

Para quantificação dos AST foi empregado o método fenol-sulfúrico (DUBOIS et al., 1956), enquanto a determinação de AR foi realizada pela técnica de SomogyNelson (NELSON, 1944), sempre em duplicata. Os teores de ANR foram estimados subtraindo-se o teor de açúcares redutores do teor de açúcares solúveis totais.

\subsection{Determinação de fenóis totais}

Para determinação do teor de fenóis totais, foi preparado o extrato etanólico com $5 \mathrm{~g}$ de folha de Parkia platycephala para obter uma concentração de sólidos de $3 \mathrm{mg} \cdot \mathrm{mL}^{-1}$, seguindo metodologia descrita em Roesler et al. (2007), sendo os testes realizados em triplicata. O teor de fenóis totais foi determinado por interpolação da absorbância das amostras contra uma curva de calibração construída com padrões de ácido gálico (10 a $350 \mu \mathrm{g} / \mathrm{mL}$ ) e expressos como mg de EAG (equivalentes de ácido gálico) por g de extrato.

\subsection{Determinação da atividade antioxidante}

A partir do extrato alcoólico, foi realizada a análise da atividade antioxidante de Parkia platycephala, em triplicata, seguindo a metodologia desenvolvida por Blois (1958). Para tanto, acrescentou-se 1,5 mL de 2,2 difenil-1-picril hidrazil (DPPH) à 0,5 $\mathrm{mL}$ de amostra seguido da leitura em espectrofotômetro a 517 nm após 30 minutos do início da reação. A leitura foi realizada com quatro concentrações diferentes $(0,001$; 0,01; 0,1 e 1,0 mg/mL), obtidas a partir da concentração do extrato inicial.

O decréscimo na leitura da densidade óptica das amostras foi correlacionado com o controle (ácido ascórbico - vitamina C) para, então, estabelecer a porcentagem de descoloração do radical DPPH. 


\subsection{Análises estatísticas}

O experimento foi em delineamento inteiramente casualizado, com 12 tratamentos (meses de janeiro a dezembro de 2017), composto por 5 repetições e unidade experimental constituída por 4 indivíduos adultos. Os dados foram submetidos à análise de variância e as médias comparadas pelo Teste de Tukey ao nível de 5\% de probabilidade, utilizando o programa estatístico Sisvar versão 5.6.

\section{RESULTADOS E DISCUSSÃO}

Os dados climáticos coletados no site do INMET mostram que a região onde foi realizado o estudo possui duas estações bem definidas: seca, de maio a outubro, e chuvosa, nos meses de janeiro a abril/novembro e dezembro. Em 2017, o mês com maior índice pluviométrico foi fevereiro, com $237 \mathrm{~mm}$, sendo que a pluviosidade anual total correspondeu a $649,6 \mathrm{~mm}$, enquanto a temperatura anual média foi de $26,61^{\circ} \mathrm{C}$ (Figura 1). Esses fatos coincidem com os dados apresentados por Soares Neto, Bezerra e Moscon (2013) que, através da observação histórica dos dados de pluviosidade, constataram que a probabilidade de precipitação anual na região de Barreiras-Bahia é inferior a $1000 \mathrm{~mm}$. Quanto à insolação, essa foi maior nos meses de maio a outubro (298,48 horas/mês), coincidindo com o período seco. Até o presente momento os valores de insolação e temperatura do mês de dezembro não foram disponibilizados no site, por isso estão ausentes (Figura 1).

Figura 1 - Índices mensais de Precipitação (mm), Insolação (horas/mês) e temperatura ambiental $\left({ }^{\circ} \mathrm{C}\right)$ no município de Barreiras (Bahia, Brasil), durante o ano de 2017

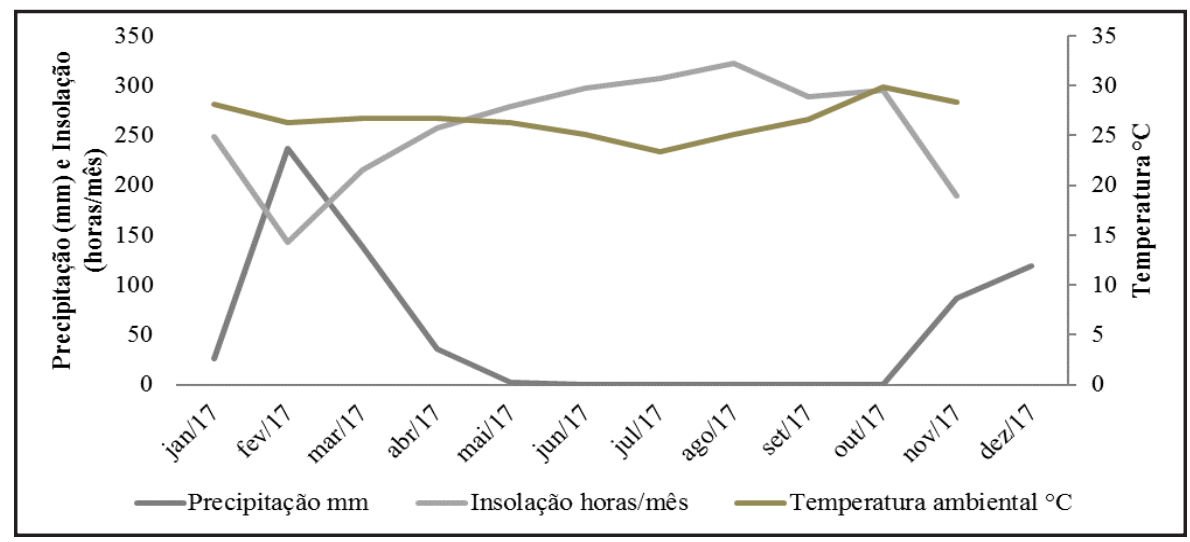

Fonte: Instituto Nacional de Meteorologia (INMET) (2018) 
Durante todo período de observação, os indivíduos de Parkia platycephala apresentaram baixa intensidade reprodutiva, com floração média de 4,60\% entre os meses de junho a novembro. O mês com maior intensidade reprodutiva foi julho, com $10 \%$ de sua capacidade total de produção de botões florais. Com relação às demais fases reprodutivas, a intensidade fenológica não alcançou 3\% da capacidade total (Figura 2A). Apesar da baixa porcentagem reprodutiva de Parkia platycephala, pode-se observar que seu período de reprodução se estendeu por toda estação seca e parte da estação chuvosa, apresentando floração prolongada, com duração de oito meses. A dinâmica reprodutiva dessa espécie caracteriza-se como anual, segundo a classificação de Newstron, Frankie e Baker (1994), completando apenas um ciclo reprodutivo durante todo o ano. A baixa intensidade reprodutiva da população estudada pode ser consequência do estádio sucessional da área do estudo, como demonstrado por Pezzini et al. (2014), em pesquisa realizada no Parque Estadual Mata Seca (Minas Gerais), onde observaram que a reprodução é mais intensa no estágio inicial de sucessão, enquanto nos estágios avançados essa intensidade só é observada na estação seca. Todavia, são necessários estudos que relacionem antropização ambiental e a fenologia de Parkia platycephala para comprovação dessa hipótese.

Quanto à fenologia vegetativa de Parkia platycephala, houve pouca variação na porcentagem de folhas maduras de janeiro a julho, quando a abscisão foliar começou a se intensificar e a porcentagem de folhas maduras decresceu $20 \%$ em agosto, chegando a zero em outubro. Esse fato coincidiu com o período em que a disponibilidade hídrica no ambiente estava baixa e os níveis de insolação altos. Todavia, a brotação aumentou em setembro e teve seu pico em outubro, alcançando 67,5\% da capacidade total, coincidindo com o período de perda total de folhas maduras. Em novembro, a intensidade de brotação voltou a decrescer, sendo que neste período os espécimes de Parkia platycephala demonstraram 77,5\% de produção de folhas jovens (Figura 2B). Esse padrão fenológico é denominado como semidecidual sazonal (LENZA; KLINK, 2006). No entanto, em estudo fenológico realizado com leguminosas arbóreas em uma área de cerrado marginal no município de Santa Quitéria, Nordeste do Maranhão, Parkia platycephala foi caracterizada como decídua tardia. Espécies caracterizadas como 
decíduas ou semidecíduas com renovação tardia das folhas na seca podem tratar-se de sempre-verdes facultativas, podendo ocorrer devido à intensidade da seca naquele ambiente em que a espécie está presente ou mesmo a incidência de fogo (BULHÃO; FIGUEIREDO, 2002). A literatura traz que a senescência foliar sazonal juntamente com a abscisão ajudam a otimizar a eficiência fotossintética, atuando na manutenção do potencial hídrico do indivíduo e na remobilização de nutrientes orgânicos e minerais para a produção de novos órgãos, como folhas e estruturas reprodutivas (TAIZ et al., 2017), indicando que esse pode ser um mecanismo utilizado por Parkia platycephala, uma vez que a rebrota ocorreu logo após a total abscisão nos espécimes estudados.

Figura 2 - Porcentagem da intensidade fenológica reprodutiva e vegetativa de Parkia platycephala relacionada à precipitação $(\mathrm{mm})$ e insolação (horas/mês) no município de Barreiras (Bahia, Brasil), durante o ano de 2017

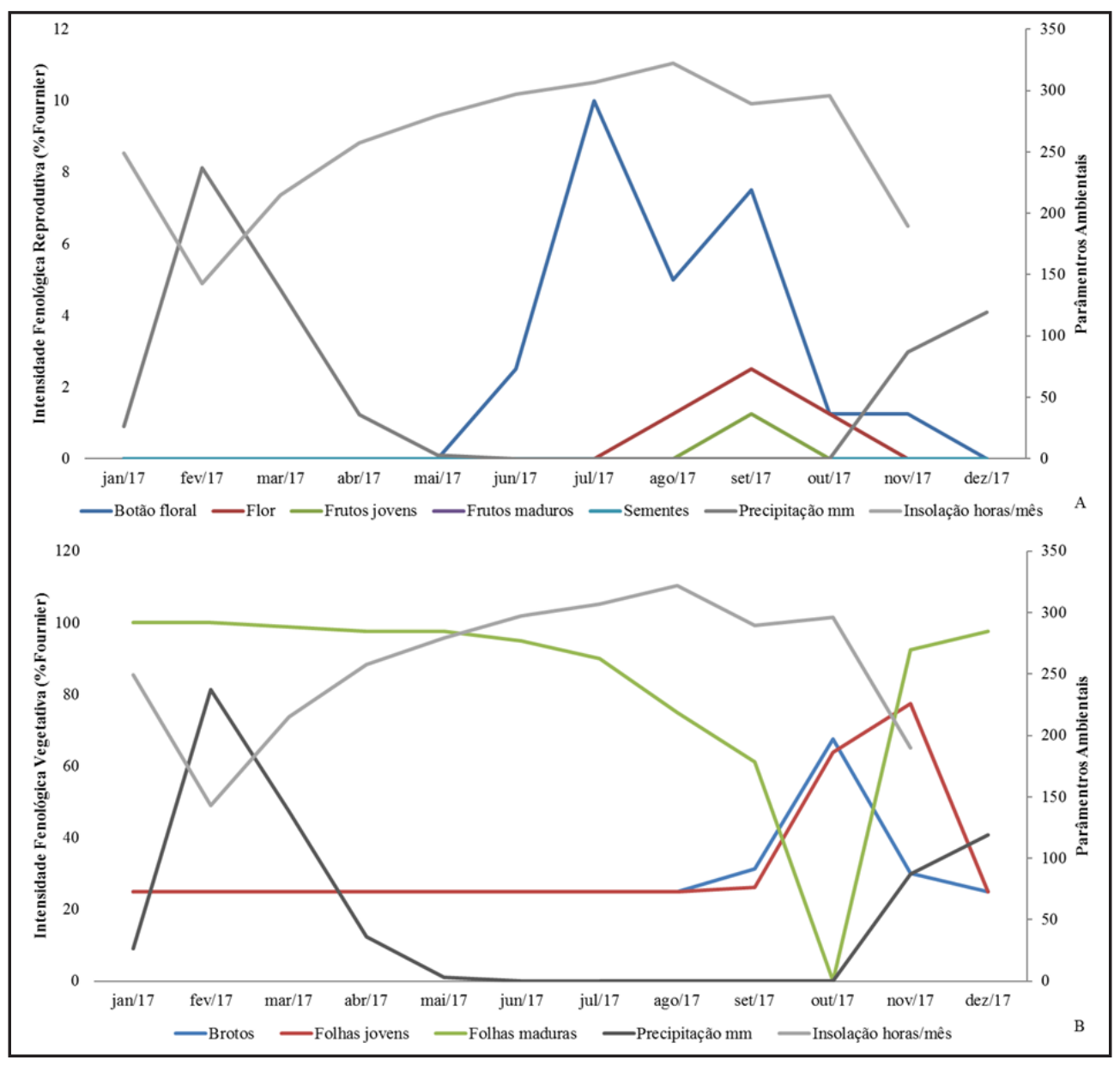

Fonte: Autoras (2018) 
A produção fotossintética em Parkia platycephala, aparentemente, também sofreu algumas alterações durante $o$ ano de observação. $O$ teor de clorofila total foi $42,86 \%$ maior nos meses de fevereiro a julho, quando comparado aos demais meses do ano, indicando uma alta atividade fotossintética, enquanto em outubro verificouse o menor teor de clorofila total, compreendendo apenas 3,29\% do teor anual desses pigmentos (Figura 3A). Isso pode ser justificado devido ao estádio inicial de desenvolvimento das folhas nesse período, que se encontravam em fase de intenso crescimento e atuando como dreno (GRIFFITHS; PAUL; FOYER, 2016).

Figura 3 - Teor dos pigmentos fotossintéticos (A) e razão entre os pigmentos fotossintéticos (B) de Parkia platycephala em função da variação hídrica e da insolação no município de Barreiras (Bahia, Brasil), durante o ano de 2017

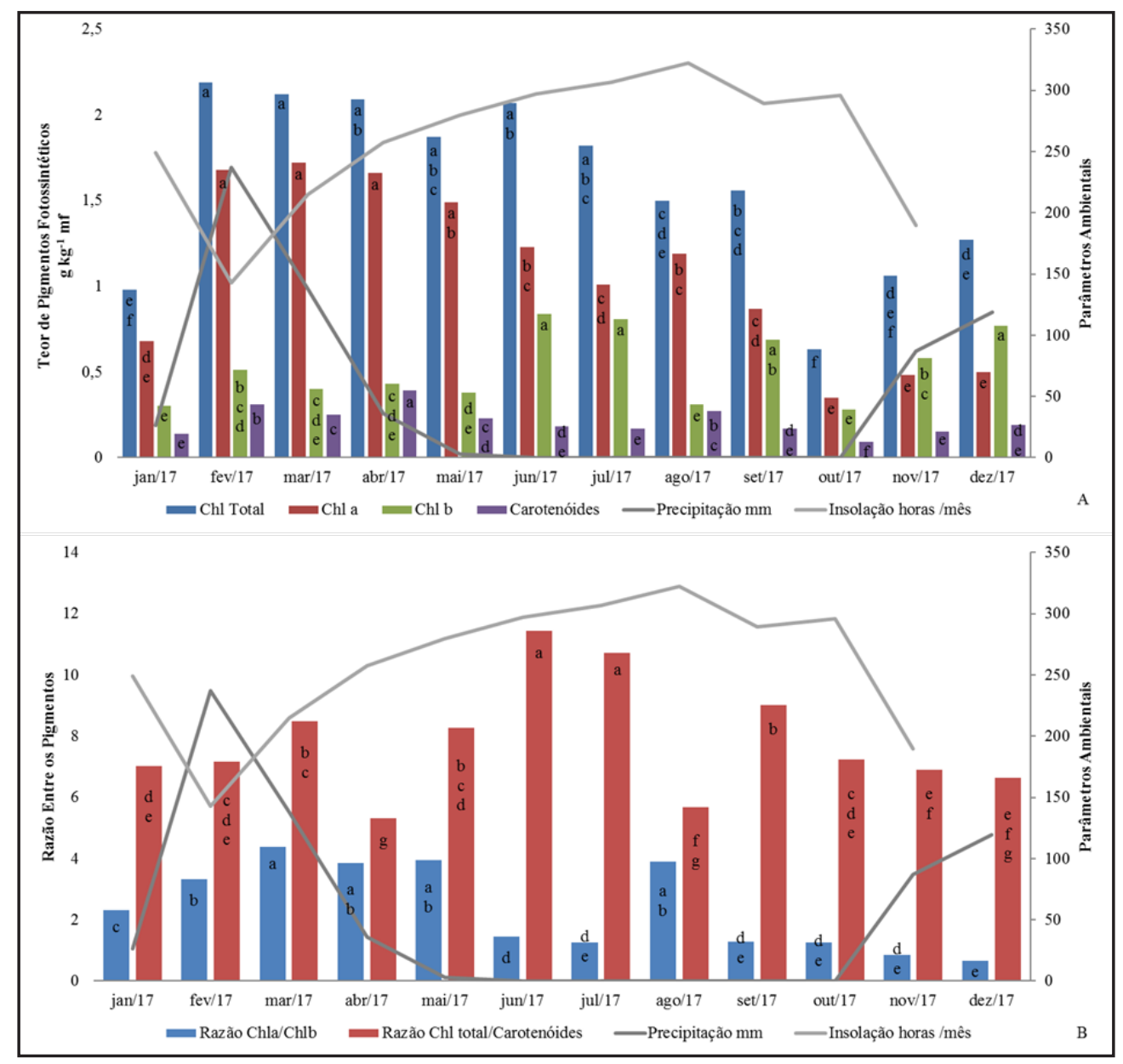

Fonte: Autoras (2018)

Em que: Chla - clorofila a; Chlb - clorofila b; Chl total - clorofila total; mf massa fresca. As médias foram comparadas pelo Teste de Tukey ao nível de $5 \%$ de probabilidade. Médias seguidas da mesma letra, nas séries, não diferem significativamente pelo teste de Tukey $(p \leq 0,05)$. 
A clorofila a teve sua maior concentração nos meses de fevereiro a maio de 2017, correspondendo a 51,05\% da produção anual desse pigmento. Nos meses de junho e julho houve um declínio de 31,7\% no teor de clorofila a e aumento de $47,88 \%$ na clorofila b (Figura 3A). A queda no teor de clorofila a pode ser resultado do agravamento do déficit hídrico juntamente com altas concentrações de compostos fenólicos, gerando a degradação desse pigmento (RAMíREZ et al., 2014). Já foi demonstrado que a clorofila a é mais sensível ao déficit hídrico quando comparada à clorofila b, justificando o decréscimo na concentração do primeiro e aumento no teor do segundo durante o período seco (MELO et al., 2017). Em relação aos carotenoides, esses apresentaram sua maior concentração em abril, com um ganho de 19,35\% em relação a março, quando houve uma queda de $73,93 \%$ na precipitação e aumento de $16,54 \%$ na insolação (Figura 3A). Esse aumento indica um papel fotoprotetor dos carotenoides em Parkia platycephala através dos mecanismos denominados quenching fotoquímico e não fotoquímico, mantendo a integridade do aparato fotossintético dessa espécie mesmo em condições de estresse (GOULD et al., 2018).

No geral, a razão clorofila a/b foi maior nos meses com maior disponibilidade hídrica e baixa insolação, compondo $62,68 \%$ do valor observado durante o ano. Isso confirma a sensibilidade da clorofila a ao estresse desencadeado por esses fatores ambientais (Figura 3B). Essa maior sensibilidade da clorofila a em relação à clorofila b pode estar relacionada à via de degradação desses pigmentos, uma vez que a degradação da clorofila b se dá com a extração do magnésio central da clorofila a pela proteína SGR (Stay-Green Rice) que, então, ativa a degradação da clorofila b por induzir a expressão de NYC1 (Non-Yellow Coloring 1) (SATO et al., 2018).

Nos meses de abril e agosto notou-se as menores razões de clorofila/ carotenoides em Parkia platycephala, sendo de 5,31 e 5,68, respectivamente (Figura 3B). As mudanças nas taxas desses pigmentos pode ser uma resposta à alta insolação e à queda na disponibilidade hídrica do ambiente, levando as plantas a ativarem o processo de fotoproteção por meio da transferência de elétrons para os carotenoides que dissipam o excesso de energia, evitando ou diminuindo os danos no aparato fotossintético (GOULD et al., 2018). Todavia, o aumento da razão clorofila/ 
carotenoides logo no mês seguinte demonstra que Parkia platycephala desenvolve respostas de defesa no momento inicial das condições de estresse, voltando a sua condição de equilíbrio logo em seguida, mesmo sem haver mudanças ambientais. De modo geral, a razão clorofila/carotenoide foi 20,68\% menor na estação chuvosa quando comparados à estação seca, podendo indicar que essa espécie possui um alto potencial de aclimatação às intemperes climáticas a que é submetida. Outro processo que pode ter acarretado a diminuição no teor de carotenoides na estação seca é a síntese do ácido abscísico, uma vez que esse hormônio está envolvido nos mecanismos de resposta da planta ao estresse hídrico e sua rota biossintética se inicia com um precursor de carotenoide (TAIZ et al., 2017).

A produção de açúcares solúveis totais (AST) teve um aumento no final da estação chuvosa, chegando a corresponder a 21,52\% de toda a produção em Parkia platycephala no ano de estudo (Figura 4). Essa alta no teor de AST pode ser devido à intensa atividade fotossintética, uma vez que nesse período do ano a disponibilidade hídrica ainda não era um fator limitante para as trocas gasosas, sendo um momento propício para a fixação de carbono. Além disso, este incremento pode ser um mecanismo de defesa contra o déficit hídrico nos meses posteriores, como demonstrado por Li et al. (2016), que perceberam uma sensibilidade do sistema envolvido no metabolismo de carboidratos às mudanças no ambiente, originando alterações na produção e acúmulo dessas moléculas no interior das plantas. Um outro fator importante para o aumento do AST é a preparação fisiológica de Parkia platycephala para a fase reprodutiva, uma vez que diferentes fases do desenvolvimento do vegetal demanda uma maior quantidade de energia (GOUGH et al., 2010). Essa hipótese é confirmada com a queda nos teores de AST e AR (açúcar redutor) a partir do mês de junho, concomitante ao início da floração (Figura 4).

Durante todo ano foi observada a dominância dos ARs em Parkia platycephala, apresentando as maiores concentrações no final da estação chuvosa com um aumento médio de 46,34\% em relação ao mês anterior. Apesar do decréscimo de 46,55\% no mês de junho, os teores de ARs se mantiveram altos durante toda a estação seca, correspondendo a 56,38\% de toda produção desses açúcares durante o ano (Figura 4). 
A elevada concentração dos ARs em Parkia platycephala durante o período seco pode representar um mecanismo de resposta ao déficit hídrico nesse período, uma vez que esses compostos já foram apontados como responsáveis por manter o potencial osmótico das plantas quando submetidas ao estresse hídrico (BRUM et al., 2013).

Figura 4 - Teor de carboidratos não estruturais de Parkia platycephala em função da variação hídrica no município de Barreiras (Bahia, Brasil), durante o ano de 2017

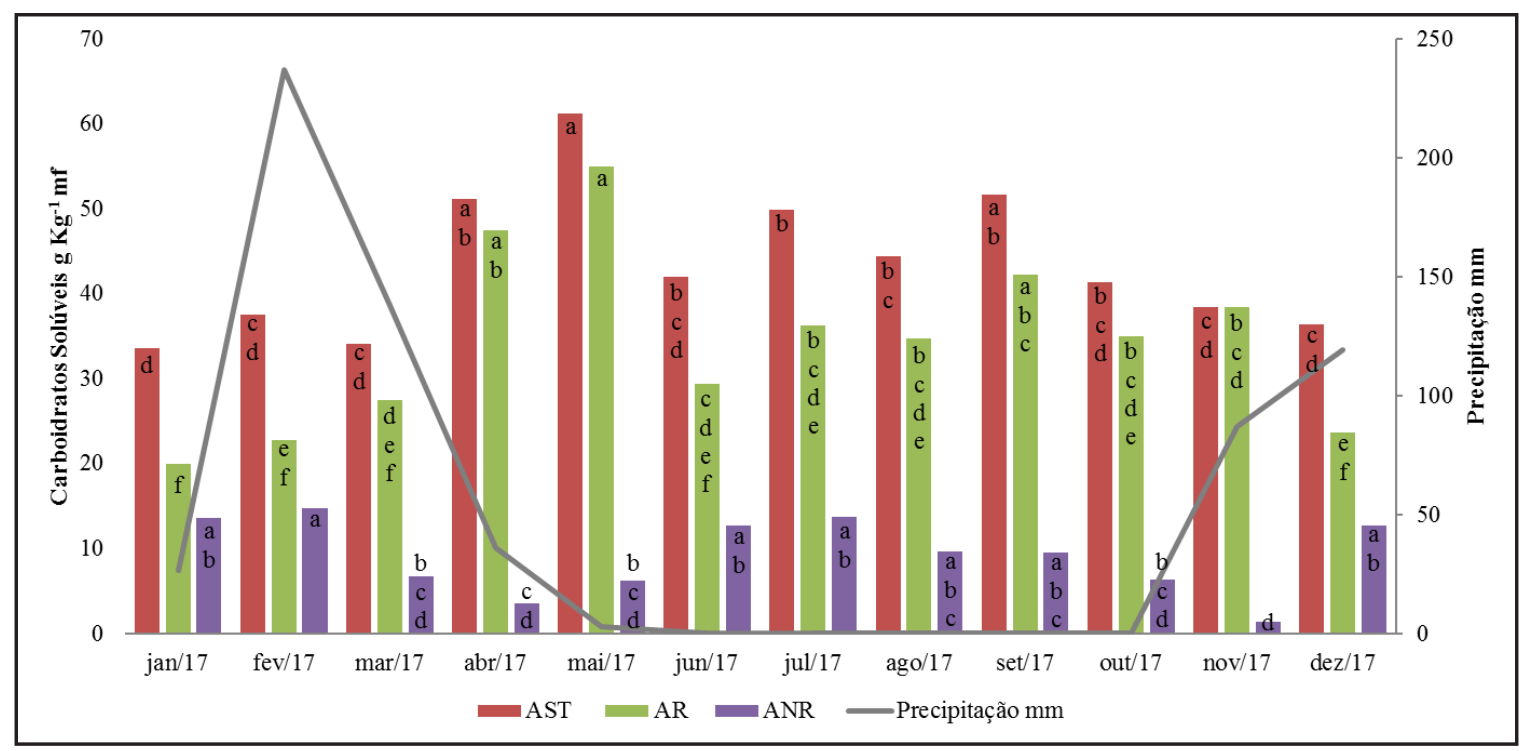

Fonte: Autoras (2018)

Em que: AST - Açúcar Solúvel Total; AR - Açúcar Redutor; ANR - Açúcar Não-Redutor. As médias foram comparadas pelo Teste de Tukey ao nível de $5 \%$ de probabilidade. Médias seguidas da mesma letra, nas séries, não diferem significativamente pelo teste de Tukey $(p \leq 0,05)$.

Com relação ao açúcar não redutor (ANR), houve decréscimo nas taxas desses compostos de $61,13 \%$ no fim da estação chuvosa (março a maio) e 66,23\% no fim da estação seca (outubro e novembro) (Figura 4). Durante o fim da estação chuvosa, além das condições ótimas para fotossíntese, também foram os meses que antecederam o início da fase reprodutiva em Parkia platycephala, houve uma maior demanda energética para a formação de órgãos reprodutivos. Enquanto, no fim da estação seca, as folhas estavam em estádio inicial de desenvolvimento, com seu aparato fotossintético ainda em formação e, portanto, atuando como dreno na planta. A alta 
concentração de ANR nos demais meses do ano demonstra que a espécie em estudo mantém sua produção fotossintética nos meses com as melhores condições para a fixação de carbono (dezembro a fevereiro) e acumula esses carboidratos para utilizálos como osmorregulador e fonte de energia na estação seca para a formação de órgãos (junho a setembro).

Além das alterações no metabolismo primário em Parkia platycephala, as mudanças ambientais também afetaram seu metabolismo secundário. Essas mudanças podem ser observadas nas flutuações nos valores de fenóis totais. De modo geral, os teores de fenóis totais se mantiveram altos durante toda a estação seca e de intensa insolação (72,17\%), com seus maiores níveis nos meses de abril, maio e agosto, compondo 35,69\% da concentração total desses compostos durante o ano de estudo (Figura 5). Esse resultado confirma o que já é citado na literatura, mostrando que fatores como forte insolação, duração dos dias, diferença entre a temperatura ambiental de dia e de noite, irregularidade na precipitação e seca podem induzir a biossíntese de compostos fenólicos (COSMULESCU; TRANDAFIR, 2011).

Figura 5 - Teor de fenóis totais em Parkia platycephala em função da variação hídrica (mm) e da insolação (horas/mês) no município de Barreiras (Bahia, Brasil), durante o ano de 2017

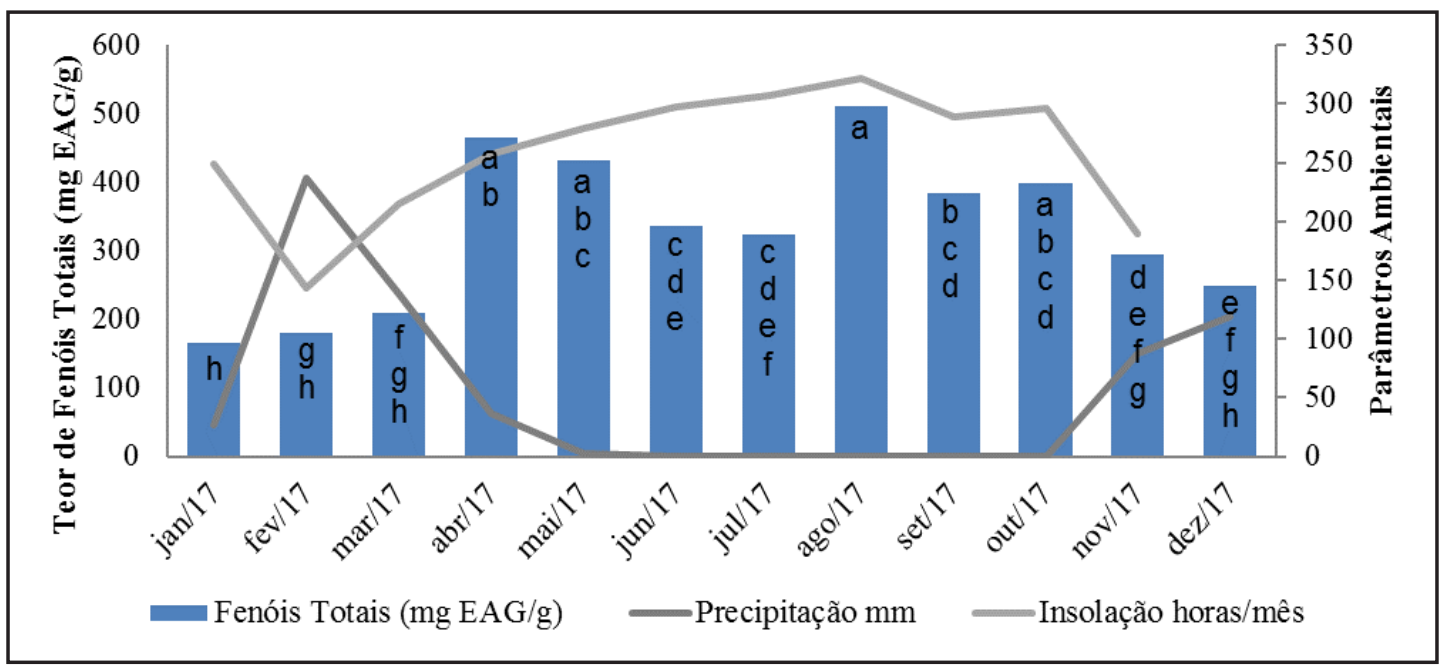

Fonte: Autoras (2018)

Em que: As médias foram comparadas pelo Teste de Tukey ao nível de $5 \%$ de probabilidade. Médias seguidas da mesma letra, nas séries, não diferem significativamente pelo teste de Tukey. 
Apesar das altas concentrações de fenóis totais nos meses de maio a agosto, Parkia platycephala apresentou suas menores taxas de atividade antioxidante (Figura 6) neste período. Isso indica que a função dos compostos fenólicos nessa espécie pode variar conforme a intensidade e o tipo de fatores de estresse. Uma vez que nesses meses a insolação e o déficit hídrico se intensificaram, a síntese de compostos fenólicos como flavonóis pode ter sido estimulada levando ao acúmulo dessas moléculas na epiderme das folhas, formando uma camada de proteção contra o excesso de radiação UV-B e evitando danos em estruturas fundamentais ao indivíduo (NENADIS et al., 2015).

No geral, as folhas de Parkia platycephala apresentaram uma alta taxa de atividade antioxidante, sendo 3,66 vezes superior ao ácido ascórbico (Vitamina C), com a concentração de $1 \mathrm{~g}$ apresentando a maior ação antioxidante, com média de $13,77 \%$ superior às demais concentrações. É importante ressaltar que o mecanismo antioxidante não enzimático de Parkia platycephala foi 13,61\% maior na estação chuvosa (Figura 6). Esses resultados podem indicar que o mecanismo antioxidante enzimático atua como via principal de combate às espécies reativas de oxigênio durante o déficit hídrico, uma vez que a atividade antioxidante não enzimática diminuiu no período em que o déficit hídrico e a insolação foram mais intensos. Entretanto, com o decréscimo na atividade antioxidante em Parkia platycephala durante a estação seca, pode-se supor que a via principal de controle aos radicais livres nessa espécie advém da atividade do sistema antioxidante enzimático. Em estudo com Capparis ovata Desf. (Capparaceae), uma espécie resistente à seca, foi demonstrado que há um aumento na atividade do sistema antioxidante enzimático durante o estresse hídrico, diminuindo assim a lesão oxidativa e aumentando a tolerância dessa espécie à seca (OZKUR et al., 2009), podendo esse ser o caso de Parkia platycephala. Todavia, são necessários mais estudos sobre o sistema antioxidante enzimático e não enzimático dessa espécie para esclarecer essas hipóteses. 
Figura 6 - Porcentagem da atividade antioxidante em Parkia platycephala em função da variação hídrica (mm) e da insolação (horas/mês) no município de Barreiras (Bahia, Brasil), durante o ano de 2017

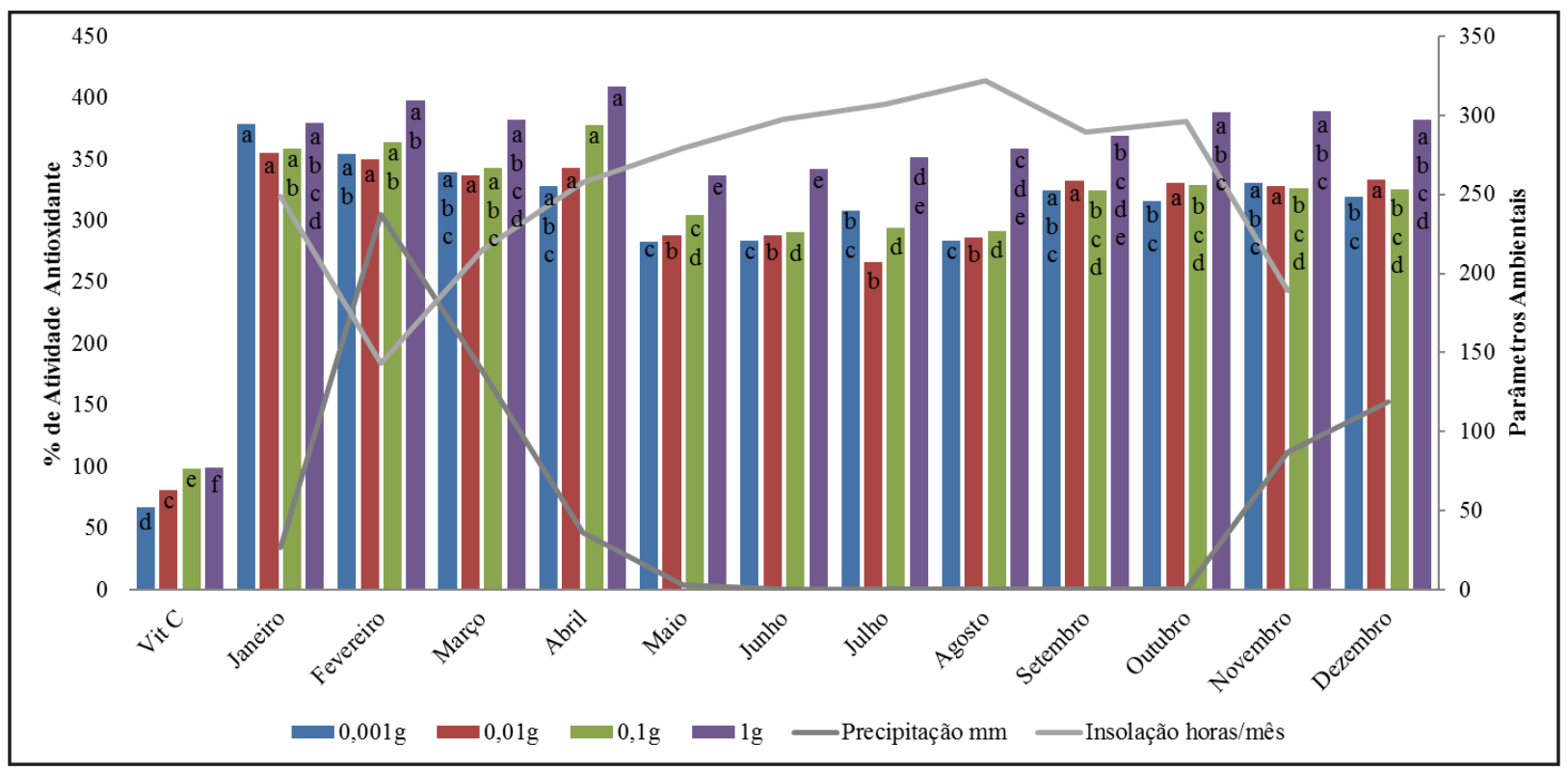

Fonte: Autoras (2018)

Em que: As médias foram comparadas pelo Teste de Tukey ao nível de 5\% de probabilidade. Médias seguidas da mesma letra, nas séries, não diferem significativamente pelo teste de Tukey.

\section{CONCLUSÕES}

Durante o período de estudo, Parkia platycephala caracterizou-se como uma espécie altamente adaptada às condições de Cerrado, com padrão fenológico reprodutivo classificado como anual e padrão vegetativo caracterizado como semidecidual sazonal.

O teor de carboidrato e as fases fenológicas em Parkia platycephala mostraram estar condicionadas às mudanças na disponibilidade hídrica, enquanto a produção de clorofila total manteve-se elevada durante a maior parte do ano, porém a clorofila a apresentou sensibilidade aos altos níveis de insolação e intensificação do déficit hídrico. 
O teor de fenóis totais também foi afetado pelo déficit hídrico, havendo aumento nas concentrações desses compostos durante o período mais seco, enquanto a atividade antioxidante não enzimática não demonstrou ser a principal via de defesa de Parkia platycephala contra as intemperes ambientais estudadas.

Dessa forma, a espécie demostrou possuir mecanismos eficazes para manter seus processos fisiológicos ativos suportando a seca e a intensa insolação durante o ano, porém a produção de carboidratos é afetada por essas variações ambientais refletindo negativamente sobre as suas fenofases, principalmente sobre a fenofase reprodutiva.

\section{REFÊRENCIAS}

BLOIS, M. S. Antioxidant determinations by the use of a stable free radical. Nature, [s. I.], v. 181, p. 1199-1200, abr. 1958.

BRUM, C. N. F. et al. Modifications in the metabolism of carbohydrates in, (Coffea arabica L. Cv. siriema) seedlings under drought conditions. Coffee Science, Lavras, v. 8, n. 2, p. 140-147, abr./jun. 2013.

BULHÃO, C. F.; FIGUEIREDO, P. S. Fenologia de leguminosas arbóreas em uma área de cerrado marginal no nordeste do Maranhão. Revista Brasileira de Botânica, São Paulo, v. 25, n. 3, p. 361-369, set. 2002.

COSMULESCU, S.; TRANDAFIR, I. Seasonal variation of total phenols in leaves of walnut (Juglans regia L.). Journal of Medicinal Plants Research, [s. I.], v. 5, n. 19, p. 4938-4942, set. 2011.

DUBOIS, M. et al. Colorimetric method for determination of sugars and related substances. Analytical Chemistry, [s. I.], v. 28, n. 3, p. 350-356, mar. 1956.

FOURNIER, L. A. Un método cuantitativo para la medición de características fenológicas en árboles. Turrialba, San José, v. 24, n. 4, p. 422-423, out./dec. 1974.

GOUGH, C. M. et al. Phenological and temperature controls on the temporal non-structural carbohydrate dynamics of Populus grandidentata and Quercus rubra. Forests, [s. I.], v. 1, p. 6581, mar. 2010.

GOULD, K. S. et al. When are foliar anthocyanins useful to plants? Re-evaluation of the photoprotection hypothesis using Arabidopsis thaliana mutants that differ in anthocyanin accumulation. Environmental and Experimental Botany, [s. I.], v. 154, p. 11-12, out. 2018.

GRIFFITHS, C. A.; PAUL, M. J.; FOYER, C. H. Metabolite transport and associated sugar signalling systems underpinning source/sink interactions. Biochimica et Biophysica Acta, [s. I.], v. 1857, n. 10, p. 1715-1725, out. 2016.

HOPKINS, H. C. F. Parkia: leguminosae: mimosoideae. Flora Neotrópica, New York, v. 43, n. 2, p. 1-123, out. 1986. 
LENZA, E.; KLINK, C. A. Comportamento fenológico de espécies lenhosas em um cerrado sentido restrito de Brasília, DF. Revista Brasileira de Botânica, São Paulo, v. 29, n. 4, p. 627638, out./dez. 2006.

LI, L.; SHEEN, J. Dynamic and diverse sugar signaling. Current Opinion in Plant Biology, [s. I.], v. 33, p. 116-125, out. 2016.

LI, N. et al. Leaf non-structural carbohydrates regulated by plant functional groups and climate: Evidences from a tropical to cold-temperate forest transect. Ecological Indicators, [s. I.], v. 62, p. 22-31, mar. 2016.

LICHTHENTHALER, H. K. Chlorophylls and carotenoids: pigments of photosynthetic biomembranes. Methods in Enzymology, [s. I.], v. 148, p. 350-382, 1987.

LORENZI, H. Árvores brasileiras: manual de identificação e cultivo de plantas arbóreas nativas do Brasil. Nova Odessa: Instituto Plantarum, 2002. 174 p.

MELO, H. F. D.; SOUZA, E. R. D.; CUNHA, J. C. Fluorescence of chlorophyll a and photosynthetic pigments in Atriplex nummularia under abiotic stresses. Revista Brasileira de Engenharia Agrícola e Ambiental, Campina Grande, v. 21, n. 4, p. 232-237, abr. 2017.

MORELLATO, L. P. C. et al. Linking plant phenology to conservation biology. Biological Conservation, [s. I.], v. 195, p. 60-72, mar. 2016.

NELSON, N. A photometric adaptation of Somogy method for determination of glucose. Journal Biology Chemistry, [s. I.], v. 135, n. 2, p. 136-75, fev. 1944.

NENADIS, N. et al. Interactive effects of UV radiation and reduced precipitation on the seasonal leaf phenolic content/composition and the antioxidant activity of naturally growing Arbutus unedo plants. Journal of Photochemistry \& Photobiology, [s. I.], v. 153, p. 435-444, dez. 2015.

NEWSTRON, L. E.; FRANKIE, G. W.; BAKER, H. G. A new classification for plant phenology based on flowering patterns in lowland tropical rain forest trees at La Selva, Costa Rica. Biotropica, [s. I.], v. 26, n. 2, p. 141-159, jun. 1994.

OZKUR, O. et al. Physiochemical and antioxidant responses of the perennial xerophyte Capparis ovate Desf. to drought. Environmental and Experimental Botany, Amsterdam, v. 66, n. 3, p. 487-492, set. 2009.

PEZZINI, F. F. et al. Changes in tree phenology along natural regeneration in a seasonally dry tropical forest. Plant Biosystems, [s. I.], v. 148, n. 5, p. 965-974, fev. 2014.

RAMÍREZ, D. A. et al. Chlorophyll concentration in leaves is an indicator of potato tuber yield in water-shortage conditions. Scientia Horticulturae, [s. I.], v. 168, p. 202-209, mar. 2014.

REDDY, A. R; CHAITANYA, K. V.; VIVEKANANDAN, M. Drought-induced responses of photosynthesis and antioxidant metabolism in higher plants. Journal of Plant Physiology, [s. I.], v. 161, n. 11, p. 1189-1202, nov. 2004.

ROESLER, R. et al. Atividade antioxidante de frutas do cerrado. Ciência e Tecnologia de Alimentos, Campinas, v. 27, n. 1, p. 53-60, jan./mar. 2007. 
SATO, T. et al. Mg-dechelation of chlorophyll a by Stay-Green activates chlorophyll b degradation through expressing Non-Yellow Coloring 1 in Arabidopsis thaliana. Journal of Plant Physiology, [s. I.], v. 222, p. 94-102, mar. 2018.

SILVA, F. A. M. da; ASSAD, E. D.; EVANGELISTA, B. A. Caracterização climática do Bioma Cerrado. In: SANO, S. M.; ALMEIDA, S. P.; RIBEIRO, J. F. Cerrado: ecologia e flora. Planaltina: Embrapa Cerrados, 2008. v. 1, p. 69-88.

SOARES NETO, J. P.; BEZERRA, A. R. G; MOSCON, E. S. Probabilidade e análise decadal da precipitação pluvial da cidade de Barreiras-Bahia, Brasil. Revista Brasileira de Geografia Física, [s. I.], v. 6, n. 3, p. 470-477, set. 2013.

TAIZ, L. et al. Fisiologia e desenvolvimento vegetal. 6. ed. Porto Alegre: Editora Artmed, 2017. $858 \mathrm{p}$.

THE BRAZIL FLORA GROUP - BFG. Growing knowledge: an overview of Seed Plant diversity in Brazil. Rodriguésia, Rio de Janeiro, v. 66, n. 4, p. 1085-1113. 2015.

\section{Contribuição de Autoria}

\section{1 - Valdelice Oliveira Lacerda}

Bióloga, Ma.

https://orcid.org/0000-0003-3844-8540•vallacerda.vl@gmail.com

Contribuição: Conceituação, Curadoria de dados, Análise Formal, Investigação, Metodologia, Administração do projeto, Visualização de dados, Escrita - primeira redação

\section{2 - Ana Maria Mapeli}

Bióloga, Dra., Professora

https://orcid.org/0000-0001-8313-4183•mmapeli@ufob.edu.br

Contribuição: Conceituação, Curadoria de dados, Obtenção de financiamento, Investigação, Metodologia, Recursos, Supervisão, Escrita - revisão e edição

\section{Como citar este artigo}

Lacerda, V. O.; Mapeli, A. M. Efeitos da sazonalidade sobre a fenologia e a fisiologia de Parkia platycephala Benth (Fabaceae, Caesalpinioideae) em área de Cerrado. Ciência Florestal, Santa Maria, v. 31, n. 3, p. 1344-1363, 2021. DOI 10.5902/1980509839111. Disponível em: https://doi. org/10.5902/1980509839111. Acesso em: xx mês-abreviado. 2021. 